\title{
Medical research, innovation and practice: the ethics of sex and gender
}

\author{
Maithree Wickramasinghe \\ Department of English, University of Kelaniya, Sri Lanka \\ DOI: https://doi.org/10.4038/jccpsl.v25i1.8202
}

Received on: 19 January 2019

Accepted on: 25 March 2019

Traditionally, the word 'sex' has been used to classify a person as a man or woman - depending on his or her physical appearance and biology (i.e. the physical, chemical, chromosomal, gonadal, anatomical and microbial composition of an individual). Gender, on the other hand, is the idea of the socially and culturally constructed differences between men and women - depending on the extent to which women and men have been 'socialised' or have 'learned' gender from their childhood onwards (1).

Socially-constructed differences or 'gender' can 'artificially' extend or exaggerate the 'natural' differences of sex. Yet often, our overall perceptions of women and men do not always coincide with reality as they are frequently based on predominant assumptions and stereo-types about gender differences - and therefore, about differences in - gendered identities, gendered roles, gendered responsibilities, gendered characteristics, gendered behaviours and conduct, gendered appearances and dress codes, gendered work, etc (2). Yet, today, sex can no longer be taken as a completely natural, static or even irreversible phenomenon - with the introduction of artificial insemination, in vitro fertilization, sex reassignment surgery, trans-gendering procedures, and other scientific innovations and interventions to the physical body. Moreover, combining sex and gender together, some countries (India, Pakistan, Nepal, Bangladesh, Thailand, Germany and some states in the USA) have today moved away from a dichotomous two-sex model of men and women. They have legally recognized three sexes or genders - male, female and ' $X$ ' - the non- binary. ' $\mathrm{X}$ ' would signify either inter-sex populations or transgender populations, or both. However, it must be noted that often transgender individuals may prefer to be identified by the gender that they have chosen and/ or to which they have 'trans-ed' or transgendered. Consequently, today, there is attention given to or an acknowledgement of the variations in the biological that have been previously ignored or missed. These developments in knowledge reinforce the fact that not only is the concept of gender a social construct; but so are the concepts of sex and biology (3) - given that we have conceptually, linguistically and socially created these definitions, parameters and barriers. Furthermore, based on work in related fields such as the history of sciences and the philosophy of sciences, it is important to keep in mind that even the concepts of science and medicine are likewise constructed by society.

\section{The importance of accounting for sex and gender in medical research and innovation}

Not accounting for sex and gender differences in medical research and innovation has led to the most fundamental of ethical and methodological errors. For example, despite cardiovascular disease being common to both men and women, research protocols for largescale studies of the disease have consistently failed to include adequate women in study samples until the 1990s. A meta-analysis of the literature on clinical trials of medications used to treat acute myocardial infarction during 1960-1991, found that women as a group had been included in less than $20 \%$ of these studies, and the elderly in less than $40 \%$ of studies (4). It was only 
in 1990 that the United States National Institutes of Health mandated the equal inclusion of minorities and women in all research study populations. Until such time, the exclusion of women in research populations was not considered to be of significance. Even today, there is an omission of pregnant women and women of childbearing potential (generally referred to with the acronym WOCBP) from research study samples. Consequently, the above categories of women are unable to benefit from these drugs.

There are three issues to be considered when it comes to the exclusion of women. Firstly, there is the overriding assumption - that male organisms represent the norm for the species, consequently, what is of relevance to men will also be of relevance to women. This indicates a certain degree of androcentrism - in other words, the idea of the male as the standard or the norm in terms of the research subject (5). Secondly, there is the issue of inclusion and representation of women - a matter of acknowledging sex differences and related gender rights (5). On principle, both men and women should be equally contained in study populations - unless it is a single sex research. Thirdly, there is the issue of the ethic of benefice. There is no doubt, researchers are expected to take precautions when involving vulnerable populations in medical experimentations. Yet, despite the altruism of this assumption, there is the counter-argument to be made that the exclusion of all pregnant or potentially pregnant women violates the ethic of benefice for these groups (6), given the significance of sex differences and the particularities of a natural phenomenon like pregnancy. Thus, it is argued that it is high time that the interactions and effects of trial medication on pregnancy should be studied on the basis that not doing so amounts to discrimination on the basis of pregnancy.

Not accounting for sex and gender becomes a critical ethical issue, when medical research fails to comprehend or assess sex differences in the onset and prevalence of disease and in symptoms of patients. It was only in the 1990s that the differential symptoms of cardiac arrest between women and men were recognized, legitimized and medicalised. Until then, the excessive focus on male research subjects and the virtual definition of cardiovascular disease as 'male' led to the under-diagnosis and undertreatment of these diseases in women - a distinct intrusion on the principle of doing no harm. In fact, studies conducted in
Massachusetts and Maryland, USA demonstrated that women were significantly less likely than men to undergo coronary angioplasty, angiography, or surgery when admitted to hospital with a diagnosis of myocardial infarction, angina, chronic ischaemic heart disease or chest pain (4). Further studies also reveal that women have had angina before myocardial infarction as frequently as men - and with more debilitating effects than men, yet women were referred for cardiac catheterization only half as often (7).

In discussing the assumptions about gender and the gender gap in knowledge, it is important to note that osteoporosis, traditionally defined as a disease of post-menopausal white women, have had worse outcomes including mortality for men and black women according to recent data (8). Studies are currently underway in several continents using both male and female reference populations of different races and ethnicities to determine the appropriate cut-off scores in diagnosis for both men and non-white women. At this point, it could be argued further that sex and gender (and even other identity intersections and crosscuts) are significant not only in terms of equal participation and data analysis, but also when selecting data collection methods and approaches. For example, in studying the health issues of a poverty-stricken sample population, for instance, in Vanni, Sri Lanka, it is quite possible that the women in that sample may have differential experiences of poverty as well as the conflict and post-conflict situation than the men in the sample. In which case, a standard questionnaire for both men and women (if that is the preferred choice of research method) will not work - as it may be particularly relevant to inquire into the lived experiences and challenges that these women may experience which may influence their overall health. Perhaps, there may be barriers in accessing health-related services, limitations in reliable modes of transportation during emergencies, coerced contraception and related health issues, continuing harassment from sections of the security forces and even exposure to intimate partner violence given post-conflict trauma (9). Consequently, some of the cross-cutting issues in the lives of these women may transcend a straightforward sex-gender analysis - given that women are not homogenous. It would, therefore, be more pertinent for the research participants themselves to provide inputs into the formulation and design of a questionnaire as equal and knowledgeable partners. 
There are methodological issues in medical innovation and experimental trials arising from sex and gender differences. While there have been many reasons for the withdrawal of drugs from the US market, one critical reason is that they fail on women (10). A 2011 study at Mayo Clinic as well as other studies have conveyed that sometimes research can end up utilizing cells and tissues derived only from males - whether human or animal. Also, for the most part, information on the sex of the cell (whether it originates from a woman or a man) is not reported at all (11). Shiebinger L discusses how in an international collaboration between laboratories in Norway and Australia, there were problems when working on bone marrow stem cells in a sample of mice (10). Researchers in the laboratory used both male and female mice in the research (certainly an excellent research design), but they happen to use all-female stem cells - resulting in the death of male mice. At first, the researchers could not understand why - since this was an unconscious decision. This example highlights that researchers should consider all combinations of the sex of donors and recipients in laboratory and clinical research before ruling out sex as a variable. Donor recipient analysis such as this has been important in human organ transplants.

Finally, a methodological shortcoming could arise in the generalisation of research findings if sex-gender differences are not considered in the research sample. As noted earlier, if men are assumed to represent the species as a whole, it is presumed 'logical' that data obtained from an all-male sample can be generalised to all species members. Any characteristics that are dissimilar (relating to women for instance) from those of men (the norm) may be taken to represent deviations from the norm. From a research practice point, when the sexual orientation of women and men has not been considered in research on sexually transmitted diseases, sexual activities and behavioural patterns found in heterosexual populations may be inadvertently applied to homosexual populations. In one instance, such findings were problematic vis-à-vis lesbian populations. Eichler M calls this the phenomenon of 'over-generalization'(5). Clearly, care should be taken to avoid this epistemological practice of inappropriately applying theories and conclusions above and beyond the research population studied - not only in relation to sex and gender but also in research on sociological differences and intersections. This may involve research relating to race, or class or ethnicity, and even the contextual (as pointed out earlier vis-à-vis researching health issues of poverty-stricken villagers in Vanni).

Accounting for sex and gender in medical research and innovations means asking a critical - if not - an ethical question:

"Does my research or invention construct or perpetuate norms of dominant or stereotypical femininity and masculinity, and does this, in turn, lead to gender inequities and inequalities?"

Importantly, the Stanford University in the USA administers a website on 'gendered innovations' (10) that offers comprehensive guidance on how to integrate sex and gender analysis when innovating and researching in the sciences. Consequently, the methodology of integrating sex and gender into research involves not only the inclusion of women as experimental subjects but also in the choice and definition of problems and hypothesis. It means the consideration of gender in the methods and approaches used for data collection, in data analysis, and in the theories and conclusions drawn from findings, and most significantly, in the formulation of protocols and guidelines for treatment. It is therefore noteworthy, that if research is to be ethical, not offering sex-specific guidelines for disease management can, once again, lead to over-generalization and flawed treatment.

\section{The significance of accounting for sex and gender in medical practice}

Implicit gender bias on the part of some medical practitioners in patient-doctor interactions is an unacknowledged ethical issue. Generally, such bias is founded on notions of sex or gender appropriateness (5). In other words, what are considered to be the appropriate gender roles, characteristics, behaviour for each sex? One apparent case in point is that of single women when they try to discuss or obtain contraception. Interviews convey that often these women are faced with a host of questions originating in the assumptions and socio-cultural values of medical practitioners vis-à-vis the sex lives of single women. Sometimes, these practitioners appoint themselves as the moral police of young women - shaming and censoring women for sexual activities outside of marriage. It is doubtful whether the same bias is likely 
to affect single men. Such attitudes convey the presence of a double standard given the assumed characteristics, dispositions, behaviour etc. in how the two sexes are evaluated.

Implicit bias in medical practitioners becomes particularly serious when it comes to matters such as sexual and gender-based violence. A 2015 research study refers to what appears to be an overall increase in the number of women who visit hospitals, the police and NGOs to seek services, and more importantly to disclose intimate partner violence (12). Yet, they also observe, that the implicit social taboo on sexuality and the lack of legal recognition of marital rape means that sexual violence and rape within marital relationships can still remain overlooked. Moreover, intimate partner violence in women have been chiefly understood from a medico-legal perspective - focusing on physical injuries, rather than long-term psychological abuse or the significance of the multifaceted nature of this masculinist practice which spans not only the family but also the economy (when it becomes necessary for women to take time off work for injuries). On the other hand, when it comes to the issue of rape - where the legal definition of the act centres on the vagina and even though courts have, on occasion, interpreted 'penetration' creatively, it is very rarely that forensic doctors will check a male victim of violence for rape (based on evidence from within the LGBTQI community). On the whole, it could be argued that explicit bias or even implicit bias in medical practice can overlook the full sociological and psychological aspects of the etiology and pathology of disease.

All these issues are compounded by the fact that, patients, have historically lacked autonomy and authority in medical encounters. As discussed earlier, it was only recently that sex reassignment surgery was considered an appropriate medical 'treatment' for gender dysphoria. Yet, for far too long, the medical profession questioned and went so far as to erase and illegitimise the desires of transsexual people for a sex change. Similarly, inter-sex genitalia in babies were made deviant - and were either pruned or boosted at birth in order to allocate a sex identity - with no consideration given to the individual and his or her potential choices. Moreover, homosexuality has been perverted, pathologized and criminalized by the global medical profession via psychological and physiological interventions to 'normalise' individuals from the $19^{\text {th }}$ century onwards. In Sri Lanka, there has been no edicts against diversity in sexual orientation until colonial times and the advent of Christian morality and British Victorian laws (13).

The autonomy of patients has been further eroded by the bio-medicalisation of natural processes such as contraception, reproduction, childbirth, and menopause during the $20^{\text {th }}$ century. This has dispossessed the skills and expertise of women elders, medicine women and traditional midwives in many communities especially during the ethnic war when public health midwives could not access conflict-affected communities (14). Yet, such indigenous knowledges have often been devalued and invalidated simply because scientific methodology and standards do not have the capacity to capture or measure some of these non-allopathic interventions. Today, it is not only an issue of medicalisation but also of commercialization, where women now have to pay, or pay more for 'medical expertise and services', which were earlier undertaken by women themselves.

At the same time, there is overmedicalisation of male and female bodies when it comes to sexuality interventions for penis enlargement, erectile dysfunction, and labiaplasty; or, the endless focus on health, appearance and longevity leading to a billiondollar industry of cosmetic surgery, lotions, and supplements as well as the increasing number of software applications. These industries have partly appropriated healing power from physicians and government authorities and transferred them to multinational pharmaceutical companies, hospitals and medical researchers. Conversely, the growth of health information on the internet and mainstream media as well as direct consumer drug marketing in some instances have also served to empower patients and consumers, specifically women.

In summary, the mandatory inclusion of sex and gender analysis in medical research, innovation and practice is important as an ethical issue. This oration discussed the ethics of sex and gender in relation to traditional concerns of patient or participant safety; the principle of doing no harm and minimizing risk; the ethic of benefice via research; the underdiagnosis and undertreatment of disease; the overgeneralization of research findings - leading to flawed treatment; as well as implicit and explicit gender bias - including 
moral policing. It also referred to the more complicated ethical issues of inclusion, representation and possible contribution to be made by research participants; the dangers of taking the male as the norm; the medical construction of deviancy and pathology as well as the devaluation and condemnation of non-allopathic knowledge. It has also argued that issues relating to bio-medicalisation, over-medicalization, and commercialisation have become ethical challenges for the medical profession as a whole. Yet, the imperative point here is that the issues highlighted are not only ethical issues, but that they are also fundamentally methodological ones - emanating broadly from a hegemony in positivist epistemology or a positivist theory of knowledge as the only valid epistemology for the medical sciences.

An epistemology based on positivism assumes or normalises (often unconsciously) that all research should be based on the scientific tradition, founded on universal laws and empirical evidence, gathered via experimentation, surveys and trials, on the premises of objectivity, truth, actuality, deduction, reason, and deal with scientific facts, statistics and mathematical data that are taken to be free of values.

Positivism assumes that the foremost usage of research is its capacity to generalize, to establish causal relationships between variables, and to measure or quantify phenomena. Based on the points discussed, it becomes clear that such assumptions may be inaccurate and that the objectives of positivism cannot always be methodologically achieved. If the core principles of positivist scientific epistemology are not questioned, there will always be gaps in so-called scientific knowledge, a perpetuation of gender and other stereotypes and insensitivities, the marginalization and exclusion of women as well as other groups, unintentional implicit bias and sometimes even explicit prejudice, problems relating to risk and safety of patients, and overall gender and diversity inequities and inequalities.

It is important to realize that the discipline of medicine is only one more socially-constructed branch of knowledge. Its epistemology (or theory of knowledge) has no more claim to authority than any other epistemological, metaphysical or political view. As a result, science, like any other human endeavour, is prone to gaps and distortions due to the social conditioning and ideologies of scientists and researchers, their metaphysical assumptions, commercial interests, etc. Today, it is increasingly acknowledged, that excellence in research, innovation and practice can be achieved - not only by adopting inter-disciplinary approaches and mixed methodologies, but also by necessarily combining different epistemologies. In other words, by merging together and integrating diverse theories of knowledge-making, of justification, of validity, of scope and methods etc. from relevant disciplines. This requires an open mind and the understanding that it is possible to combine these epistemologies without seeing them as in conflict and as contradictory. It is imperative that this is done if medical research, innovation and practice is to be ethical and methodologically sound.

\section{References}

1. Oakley A. Sex, gender and society. London: Temple Smith, 1972.

2. Wickramasinghe M. Feminist research methodology - making meaning of meaning-making. London \& New York: Routledge, 2010.

3. Moi T. What is a woman? and other essays. Oxford: Oxford University Press, 1999.

4. Gurwitz JH, Col NF, Avorn J. The exclusion of the elderly and women from clinical trials in acute myocardial infarction. JAMA 1992; 268(11): 1417-1422.

5. Eichler M. Non-Sexist research methods: a practical guide. New York \& London: Routledge, 1988.

6. Dresser R. Wanted. Single, White male for medical research. The Hastings Centre Report 1992; 22(1).

7. Ayanian JZ \& Epstein AM. Differences in the use of procedures between women and men hospitalized for coronary heart disease. The New England Journal of Medicine 1991; 325(4): 221-225.

8. Khosala S, Amin S, Orwoll E. Osteoporosis in men. Endocrine Reviews 2008; 29(4): 441-464.

9. Guruge S, Ford-Gilboe M, Varcoe C, JayasuriyaIllesinghe V, Ganesan M, Sivayogan S, Kanthasamy $\mathrm{P}$, Shanmugalingam $\mathrm{P}$, Vithanarachchi $\mathrm{H}$. Intimate partner violence in the post-war context: women's experiences and community leaders' perceptions in the Eastern Province of Sri Lanka. PLoS One 2017; 12(3): $\mathrm{e} 0174801$.

10. Schiebinger L, Klinge I, Sánchez de Madariaga I, Paik HY, Schraudner M, Stefanick M (Eds.) (2011-2018). Gendered Innovations in Science, Health \& Medicine, Engineering and Environment.

Available from: http://ec.europa.eu/research/ gendered-innovations/ 
11. Taylor EK, Vallejo-Giraldo C, Schaible NS, Zakeri R, Miller VM. Reporting of sex as a variable in cardiovascular studies using cultured cells. Biology of Sex Differences 2011; 2(11). DOI: 10.1186/2042-6410-2-11.

12. Guruge S, Jayasuriya-Illesinghe V, Gunawardena N, Perera J. Intimate partner violence in Sri Lanka: a scoping review. Ceylon Medical Journal 2016; 60(4): 133-138.
13. Sudaththa B Thero \& Dunne CJ. Homosexuality, buddhism and Sri Lankan society. Groundviews. Available from: http://groundviews.org/2007/08/28/ homosexuality-buddhism-and-sri-lankan-society/

14. Kottegoda S. Paramparika vinnabu matavan itihasayata ekveda? (In Sinhala). Are traditional midwives history? The Women and Media Collective, Colombo, 2014. 